\title{
Proposed Training Module on Goal Setting and Decision-making Skills for Distant Learners
}

\author{
Aminu Kazeem Ibrahim ${ }^{1}$, Nebath Tanglang ${ }^{2}$ \\ ${ }^{1}$ School of Education, National Open University of Nigeria, Lagos \\ ${ }^{2}$ Directorate of Learner Support Services, National Open University of Nigeria, Lagos \\ Correspondence: Aminu Kazeem Ibrahim, School of Education, National Open University of Nigeria, Lagos
}

Received: August 6, 2015 Accepted: August 11, $2015 \quad$ Online Published: August 31, 2015

doi:10.11114/jets.v3i6.1064

URL: http://dx.doi.org/10.11114/jets.v3i6.1064

\begin{abstract}
Inappropriate goal setting and decision-making skills are threat to distant learners' completion of academic programme, development and social well-being. This was realised following two related studies carried out by the authors of this write-up in addition to facts from reviewed literatures as one of the factors responsible for low retention and completion rates among undergraduate learners in open and distance learning institution, To further $\mathrm{x}$-ray the problem, a simple survey was conducted on Student counsellors' responses with 57 Student counsellors representing $91.94 \%$ out of the 62 Student counsellors on the need to integrate training on goal setting and decision-making skills into learners support services. The findings suggested learner support services that should integrate the basic steps that were researched for setting achievable goals and decision-making skills necessary for implementing set learning goals. This paper therefore, proposed modalities that can be followed by support services unit of open and distance learning institutions in training learners diagnosed to have inappropriate goal setting and decision-making skills into modules. The modules were tested in training twelve volunteered undergraduate distance learners identified from previous study carried out by the authors. At the end of the trial testing the participated undergraduate distant learners were asked to rate the effectiveness of the activities involved in the training. The trust of the proposed module was to serve as a strategy in training the distant learners particularly, when low retention and completion rate are traced to inadequate skills for setting goals and decisions-making skills.
\end{abstract}

Keywords: goal setting, decision-making, learner, support services and retention

\section{Introduction}

One of the developments observed in open and distance university enrolment is the age range of young learners of between 17 to 20 years enrolling in the institution (National Open University of Nigeria [NOUN], 2012). This trend of development is contrary to the old views that open and distance university and programmes are for learners of old ages that are working or had work experiences (Okopi \& Ofole, 2013). This testifies that principles of flexibility, accessibility and openness in open and distance universities are taking their rightful dimensions. The new age ranges of learners possess more challenges and require an enlarged support services. Literatures particularly, those related to number of enrolment and graduation rates revealed high rate of enrolment with poor rates of completion among undergraduate distance learners of the same course of programmes (Tanglang \& Aminu, 2014). Among the notable challenges of this category of learners are the ones associated with the academic performances and achievements which sometimes started when learners involved in late submission of academic assignments, late completion of academic tasks, complain from learners of combining many activities with learning activities. Fortunately, the challenges can be linked to two major factors that is, inappropriate goal setting and decision-making skills.

The roles played by good or effective decision are vital to the overall achievement of set learning goals by distant learners both in learning / academic performance and general life engagements. Assisting learners to effectively set realistic and achievable goals and developing in the learner efficient decision-making skills are assumed to be one of the roles of distance learning institutions and providers of support services of many of the distance and open learning institution world over, particularly in the National Open University of Nigeria (Ipaye, 2003). The convention that learners must set goals and make rational decisions that will enhance their academic performance have generated different but related studies. Tanglang and Aminu (2014) findings recorded $r=0.013<0.901$ in Psychology of learning, 
$\mathrm{r}=0.086<0.391$ in Measurement and Evaluation and $\mathrm{r}=0.27>0.007$ in the Good Study Guide but, $\mathrm{r}=0.27>0.007$ in Sociology of Education between High and Low decision-making skills students. In a study on self - efficacy, one of the variables of goal setting an $r=-0.029<0.77$ decision-making skills combined with other related variables by Joo, Bong and Choi (2000) found that student's self-efficacy for self-regulated learning, positively related to his / her academic self-efficacy, strategy use, and internet self-efficacy. Chan, Yum, Ran, Jegede and Taplin (1999) compared high achieving and low achieving Open University students according to their study habits, purpose for learning, approaches to study, use of support systems, other commitments and self-perceptions, discovered that motivation is a factor affecting achievement. In another study, Roblyer (1999) worked on factors that motivate community college and virtually high school students to choose online or traditional course formats. The findings indicated that for students who choose distance learning, control over face and timing of learning was more important; for students who choose face-to-face (FTF) course interaction with instructor and students was paramount. Cheners, $\mathrm{Hu}$, and Garcia (2001) discovers that self-efficacy was related both to academic performance $(r=38)$ and to persistence $(r=34)$. In a similar context, Pajares and Kranzler (2002) demonstrated that the direct effect of mathematics self-efficacy on mathematics performance $(\mathrm{B}=349)$ was as strong as was the effect of general mental ability $(\mathrm{B}=324)$. McIsaac, and Gurawerdena (1996) opined that a combination of cognitive style, personality characteristics and self-expectations are asserted to predict the achievement in distance education. Michael (2013) examined the evidence for the effectiveness of active learning. It defines the common forms of active learning most relevant for engineering faculty and critically examined the core element of each method and found that there is broad but uneven support for the core elements of active, collaborative, cooperative and problem-based learning.

Based on the view that inappropriate goal setting and ineffective decision-making skills are responsible for the challenges posed by the new age range among open and distance undergraduate learners, the study sampled the opinions of student counsellors that are involved in providing academic and other types of related support services to learners in open and distance learning institutions on the possible causes of these challenges. It was discovered that fifty-seven (91.94\%) of the sixty-two student counsellors' sampled opinions in the sample open and distance learning university agreed that poor goal setting and ineffective decision-making skills were the possible causes of poor academic performances and achievements among young undergraduate distance learners of the university. In addition to this, Tanglang and Aminu (2015) investigated three hundred and forty- six undergraduate distance learners in an open and distance university and discovered that a statistically significant difference existed between high and low goal setter undergraduate distance learners in academic performances $(t=4.01<0.000)$, statistically significant difference between high and low decision - making skills undergraduate distance learners in academic performances $(\mathrm{t}=-3.35 .93<0.001)$, statistically significant positive relationship between high goal setter undergraduate distance learners and high decision-making skill undergraduate distance learners in academic performances $(0.297<0.000)$ and statistically significant negative relationship between low goal setter undergraduate distance learners and low decision-making skill undergraduate distance learners in academic performances $(-0.307<0.000)$ in four core courses of their chosen academic programmes. On the basis of these findings, undergraduate learners in distance learning institutions must be assisted to realise that setting achievable goals are vital to human success and achievements. And set realistic learning goals may also not enough to benefit a distance leaner academic performance without corresponding appropriate decision-making skills for the set or targeted goal. Researchers such as Locke and Latham (2002) have identified various goal properties and have investigated how different goals link with achievement outcomes. Executing a set of achievable goals will therefore depend on taking effective decision towards actualization of the set learning goals, since goals contribute to success.

These findings somehow suggested that when learners are trained through support services provided by open and distance learning institutions through their support service units on setting learning goals and working out effective decision-making skills strategies, brilliant academic performances and achievements may be attained (Aminu \& Gali, 2012). To buttress this point, education and counselling psychologists believed that learning to formulate goals and developing efficient decision-making skills are some of the basic training that should be inculcated in learners if there must be successful academic records (Shertzer \& Stone, 1976; Saka, 2006; Sambo, 2008; Aminu \& Gali, 2012). In addition, Zimmerman and Kitsantas (1999) showed that outcome goals can be highly motivating and lead to skill gains once students have acquired some competence. Teachers can shift students to focusing on outcome goals that are self-referenced such as how well students are doing currently compared with how they did previously, rather than socially referenced such as how well they are doing compared with how classmates are doing (Zimmerman \& Kitsantas)

These findings somehow suggested that when learners are trained through support services provided by open and distance learning institutions through their support service units on setting learning goals and working out effective decision-making skills strategies, brilliant academic performances and achievements may be attained (Aminu \& Gali, 
2012). To buttress this point, education and counselling psychologists believed that learning to formulate goals and developing efficient decision-making skills are some of the basic training that should be inculcated in learners if there must be successful academic records (Shertzer \& Stone, 1976; Saka, 2006; Sambo, 2008; Aminu \& Gali, 2012). Setting attainable goals determines the success of any activity. When goals are clearly mapped out, it must be accompanied with efficient decision-making skills so as to ensure it achievable implementation (Mind tools, 2014). Setting attainable goals have been traced to effective motivation. For example, Locke and Latham's theory, 1960's (cited in Mind Tools, 2014) showed that clear goals and appropriate feedback motivated individual. For undergraduate distant learners to set realistic goals, Locke and Latham (1990) outlined five principles of goal setting need to be examined. The five principles were found to improve individual chances of success and they include clarity, challenge, commitment, feedback and task complexity to develop effective decision-making skills that is needed to carry out set achievable goals also involved the following stages of decision-making: efficient evaluation of problems, list of possible solutions in term of merits and demerits, application of the most appropriate solution, acceptance of the outcomes and acting upon the outcomes (Shertzer \& Stone, 1976; Okon, 1983; Denga, 1986; Saka, 2006; Sambo, 2008; Aminu \& Gali, 2012). According to Mind Tools (2014), the stages involved in making efficient decision includes establishing a positive decision-making environment, generating potential solutions, evaluating alternatives, deciding, checking the decision, communicating and implementing the decision.

Based on the foregoing, the authors proposed a training module for undergraduate open and distance learners on goal setting and effective decision-making skills that may be used by support service units in distance learning institutions so as to enhance learners' retention and completion rates thereby, enhancing brilliant academic performances and achievements. The proposed module will take a minimum of five meetings on average of one hour and fifteen minutes to train undergraduate distance learners on setting attainable learning goals and appropriate decision-making skills to carry out the set goals. In addition, the module for the training can be used for individual or group of distance learners with similar challenges.

\section{Proposed Module for Training Goal Setting and Decision-making Skills for Individual or Group}

The main objective is to train distance learners on how to set achievable learning goal and develop appropriate decision-making skills necessary to accomplish the set goals. The training spanned within a period of five meeting contacts. The contact meetings were used to cover the five stages of the proposed module. The five stage modules are:

Stage 1 (Module 1): Student counsellor or support provider identified low goal setters and low decision-making skill learners as experiences of the authors shows that distance learner with poor learning goal also faces ineffective decision-making skills. The identified distance learner (s) are to be guided to share their experiences on academic performance challenges, engage in identification of possible causes and the student counsellor assist to reach an agreement on the importance of setting learning goals and developing effective decision-making skills for achieving the set goals through questions and answers and discussions.

Stage 2 (Module 2): During the second contact, the targeted distant learner (s) should be introduced to module 2. They should be asked to list what they would consider in setting their learning goals before, during and after their chosen academic programmes.

Stage 3 (Module 3): During the third contact, the distance learner (s) should be introduced to principles of setting attainable goals: clarity, challenge, commitment, and feedback and task complexity. At this stage also, the distance learner (s) should be instructed on how to set learning goals with the principles being outlined. Individual and group practice on this should be carried out during the session. The learner (s) should be asked to set for themselves their learning goals after the support provider or student counsellor must first demonstrate this. Homework should be given in addition to facilitate this; feedbacks were to be received during the next contact meeting. For homework: 1. the learner (s) should locate quiet place and go through the principles for setting attainable learning goals. 2. The learner (s) should use the principles to set more learning goals. 3. The learner (s) should record the satisfaction for engaging in the exercise.

Stage 4 (Module 4): During the fourth contact, Feedbacks from homework should be received and analysed. The next activities are to introduce the learner (s) into skills for developing effective decision-making needed to carry out their set learning goals. The skills involved are: efficient evaluation of problems, list of possible solutions in term of merits and demerits, application of the most appropriate solution, acceptance of the outcomes and acting upon the outcomes. In this session, the learner (s) should be guided on how the decision-making skills can be applied to the implementations of the set learning goals in module 3. Individual and group practice on this should be carried out during the session. The student counsellor or support service provider should ask the learner (s) to orally discuss how the skills for decision-making can be used to achieve the set learning goals. Homework should also be given at this stage to facilitate this; feedbacks should be received during the following contact meeting. For homework: 1. Learner (s) should be asked 
to locate quiet place and go through the decision-making skills necessary for carrying out their previously set learning goals. 2. They should discuss how these skills can be used for carrying out their previously set learning goals. 3 . They should record the satisfaction for engaging in the exercise.

Stage 5 (Module 5): During the fifth contact, feedbacks from homework should be received and analysed. The next activities, the student counsellor or support provider should assist the learner through guided discussion to highlight possible observations, questions and challenges.

\section{Trial Testing: Using the Proposed Modules to Train Goal Setting and Decision-Making Skills}

The authors tested the practicability of the module procedures on twelve (12) volunteered 100 level undergraduate open and distance learners ( 6 females and 6 males). The average age of the learners was 18 . The learners previously participated in a study conducted by Tanglang \& Aminu (2015), in which they were identified as low goal setters and decision -making skills learner. The training spanned within the period of five contact meetings. The contact meetings were divided into modules 1 to 5. The training lasted for five weeks, having contacts meetings on Saturdays only, the first contact meeting lasted for two hours and seven minutes, second contact meeting lasted for one hour and thirty-five minutes, third contact meeting lasted for two hours and forty- seven minutes, fourth contact meeting lasted for one hour forty-eight minutes and the fifth contact meeting lasted for one hour and twenty minutes. The sitting arrangement was in a circle form. After the training, the learners were requested to rate the effectiveness of the proposed module activities. Summaries of the activities during the training are given below.

A. During the first contact meeting, the learners were informed by the authors the objectives of the exercise which was to assist them in formulating achievable learning goals and developing appropriate decision-making skills for implementing their set learning goals, they were informed that the training is divided into five modules and it will last for five weeks. During the session also, the learners were asked to select a convenient meeting days and Saturday was selected fixing 10.00 am as the starting time. A group leader was appointed before being assisted to share their experiences on academic performance challenges, engaged in identification of possible causes of these problems and challenges. The authors assisted the learners to link the identified academic challenges to lack of formulated realistic learning goals and automatically resulted in ineffective decision-making skills to carry-out the goals through discussion, questions and answers. The learners were asked to list their learning goals and strategies for their accomplishment. Few of the participants tried these. The attempt made by those that listed some of their learning goals and decision strategies served as the baseline data for the study. Details of the baseline data include:

Table 1. The baseline data for group training on goal setting and decision-making skills

\begin{tabular}{|c|c|c|}
\hline Targeted skills & Frequency & Duration \\
\hline $\begin{array}{l}\text { Clarity of goals formulated } \\
\text { by the participants }\end{array}$ & $\begin{array}{c}\text { for some not clear and others } \\
\text { no clarification }\end{array}$ & $\begin{array}{l}\text { before starting the } \\
\text { university programme }\end{array}$ \\
\hline How challenging the goals & not clearly mapped out & before starting the \\
\hline Formulated by the participants & & university programme \\
\hline Demonstration of commitment & not very clear & before starting the \\
\hline To the set learning goals & & university programme \\
\hline Mechanisms for receiving & not very clear & whenever they \\
\hline $\begin{array}{l}\text { Feedbacks following achievement } \\
\text { of set learning goals. }\end{array}$ & & passed examination \\
\hline $\begin{array}{l}\text { Task complexity for carrying out } \\
\text { Set goals by participants }\end{array}$ & not very clear & not clear \\
\hline Efficient evaluation of problem by & not clear & whenever they felt \\
\hline $\begin{array}{l}\text { Participants } \\
\text { they could not }\end{array}$ & & \\
\hline Overcome & & \\
\hline Challenge & & \\
\hline $\begin{array}{l}\text { List of possible solutions in term } \\
\text { Of merits and demerits by }\end{array}$ & someone unconsciously & all the times \\
\hline Participants & & \\
\hline $\begin{array}{l}\text { Application of the most appropriate } \\
\text { Solution by participants }\end{array}$ & unconscious & not formalised \\
\hline $\begin{array}{l}\text { Acceptance of the outcomes of } \\
\text { Decision taken by the participants } \\
\text { Possible }\end{array}$ & not very clear & whenever it is \\
\hline
\end{tabular}

AS shown in table 1, the targeted skills, frequencies and durations.

During the second contact meeting, the learners were introduced to module 2 . They were asked to list factors they will consider in setting their learning goals according to their identified learning challenges. The identified factors were: Individual learning, family background status, time for learning/reading, individual peculiar nature of work, inadequate 
learning materials, poor internet connectivity, imposed learning time schedule by the university in relation to when and how learning tasks were to be submitted. These factors were discussed in group and the authors assisted the learners on how properly formulated goals and effective decision-making skills can eliminate the challenges identified.

During the third contact meeting, the learners were introduced to principles for setting attainable learning goals which includes: clarity, challenge, commitment, and feedback and task complexity. At this stage also, the learners were assisted on how to use the principles to formulate their various learning goals. Individual and group practice on this were carried out. In addition, homework that requested the learners to locate quiet place and go through the principles, used the principles to set additional learning goals and record the satisfaction derived for performing the activities included in the homework.

During the fourth contact meeting, after receiving feedbacks on homework and it generated discussions, the learners were then introduced to skills for developing effective decision-making needed to carry out their formulated learning goals. The skills involved were, efficient evaluation of problems, list of possible solutions in term of merits and demerits, application of the most appropriate solution, acceptance of the outcomes and acting upon the outcomes. The learners were also assisted on the decision-making skills that can be applied to achieve the set learning goals. Individual and group practice on these approaches include isolating a particular set of learning goal and asking the learners to suggest ways as relates to each of the decision-making skills. For example, the first skill is efficient evaluation of problem. Here a set learning goal is seen as a problem so the isolated learning goal in focus. Does the goal worth being a problem if it is, learners proceeded to the next stage that is, list of possible solutions and gradually like that. Individual learner was also asked to work and orally presented what he s/he had worked on and the other members in the group contributed. At the end of this session, homework was also given to facilitate perfection in the exercise.

During the fifth contact meeting, after receiving and discussing the feedbacks from homework given, the learners were led through guided discussions to highlight possible observations, questions and challenges. At the end, the learners were asked to assist in rating some of the activities involved in the training.

Table 2. The results of the participants rating of the effectiveness of goal setting and decision-making skills training activities

\begin{tabular}{|c|c|c|c|c|c|c|}
\hline $\begin{array}{l}\text { Activities } \\
\text { evaluated }\end{array}$ & $\begin{array}{l}\text { Not helpful } \\
\text { at al }\end{array}$ & $\begin{array}{l}\text { Not very } \\
\text { helpful }\end{array}$ & Neutral & Helpful & $\begin{array}{l}\text { Very } \\
\text { helpful }\end{array}$ & $\begin{array}{l}\text { Number } \\
\text { participants }\end{array}$ \\
\hline Group & & & & & & \\
\hline discussions & & & $5.56 \%$ & $77.78 \%$ & 16.67 & 12 \\
\hline $\begin{array}{l}\text { Individuals } \\
\text { inputs }\end{array}$ & & $6.78 \%$ & $21.00 \%$ & $55.56 \%$ & $6.67 \%$ & 12 \\
\hline Meeting & & & & $3334 \%$ & $66660 \%$ & 12 \\
\hline Usefulness & & & & $33.34 \%$ & $6666 \%$ & 12 \\
\hline $\begin{array}{l}\text { of skills learnt } \\
\text { Group }\end{array}$ & & & $16.67 \%$ & $50 \%$ & $33.34 \%$ & 12 \\
\hline $\begin{array}{l}\text { homework } \\
\text { Group }\end{array}$ & & & & $66.66 \%$ & $22.22 \%$ & 12 \\
\hline size & & & & $27.77 \%$ & $72.22 \%$ & 12 \\
\hline $\begin{array}{l}\text { Usefulness } \\
\text { of group } \\
\text { member }\end{array}$ & & & & & & \\
\hline $\begin{array}{l}\text { feedbacks } \\
\text { Group }\end{array}$ & & & $11.11 \%$ & $66.66 \%$ & $22.22 \%$ & 12 \\
\hline leader imputes & & & $5.56 \%$ & $16>67 \%$ & $77.78 \%$ & 12 \\
\hline
\end{tabular}

As shown in table 2, percentages of participants who rated their experiences in each activities and their numbers.

\section{Conclusion}

The authors made an attempt to use theorized principles of goal setting and decision-making skills to train undergraduate learners in open and distance learning institution on how the principles can be used to formulate learning goals and develop effective decision-making skills needed to carry out set learning goals. The training was limited to Twelve 100 hundred level undergraduate distance learners in open and distance learning university therefore; there is the need to elaborate the scope, to properly diagnose learner level of goal setting and decision-making skills before being encouraged for the training. The principles of goal setting being used were limited to Locke \& Latham (1990) outlined five principles of goal setting cited in Mind Tools (2015), likewise, the principles of decision-making skills were limited to Mind Tools (2014) outlined principles but supported by Shertzer \& Stone (1976); Okon (1983); Denga (1986); Saka (2006); Sambo (2008); Aminu \& Gali (2012). 


\section{Acknowledgements}

The authors are extremely grateful to many of the authors and publishers we cited or quoted from their works, and if anything is inadvertently adopted or adapted where permission should have been obtained, it is hoped that this will be excused as an oversight. The authors also thank the distant learners who voluntarily participated in the study.

\section{References}

Aminu, K. I., \& Gali, S. (2012). Guidance and counselling in schools: theories and practices. Nigeria. Kano: Albarka Publishing Company

Chan, M. S. C. et al. (1999). Locus of control and metacognition in open and distance learning: A comparative study of low and high achievers. China, Beijing. Paper presented at the $13^{\text {th }}$ Annual conference of the Asian Association of Open Universities. The Central Radio and TV University.

Cheners, M. M. et al. (2001). Academic self-efficacy and first year college students performance and adjustment' .Educational Psychology, p.55. http://dx.doi.org/10.1037/0022-0663.93.1.55

Denga, D. L. (1986). Guidance and Counseling in Non-school Setting. Nigeria. Jos: Savanna Publishers Limited. http:/www.iacsit.org

Joo, N. J. et al. (2000). Self -efficacy for self -regulated learning, academic self-efficacy and internet self-efficacy in web-based instruction. Education Technology Research and Development, 48(2). http://dx.doi.org/10.1007/BF02313398

Locke, E. A., \& Latham, G. P. (1990). A theory of goal setting and task performance. NJ: Prentice Hall Englewood Cliffs,.

Locke, E. A., \& Latham, G. P. (2002). Building a practically useful theory of goal setting and task motivation: A 35-year odyssey. American Psychologist, 57, 705-717. http://dx.doi.org/10.1037/0003-066X.57.9.705

McIsaac, M. S., \& Gunaeardena, C. N. (1996). Distance education. New York Macmillan Jonassen, Ed.

Michael, P. (2013). Does active learning works?' A Review of Research Engineering Education. 93(3), p.223. http:/www.emory.edu./EDUCATION/mfp/efftalk.html

Mind Tools (2014). How good is your goal setting?. http:/www.mindtools.com/pages/article/newTED-79htm

Mind Tools. (2014). Making an effective decision. http:/www.mindtools.com/pages/article/newTED-79htm

National Open University of Nigeria ([NOUN], 2013). Strategic plan. (2013-2017), Nigeria.

Okon, S. E. (1983). Guidance for the 6-3-3-4 system of education. Nigeria: Ahmadu Bello University: Institute of Education.

Okopi, F., \& Ofole, N. (2013). Impact of learner support services on open and distance learners in National Open University of Nigeria. Nigeria: West African Journal of Open and Distance Learning.

Pajares, F. (2002). Self-efficacy beliefs in academic contexts. http:/www.emory.edu./EDUCATION/mfp/efftalk.html

Roblyer, M. D. (1999). Is choice important in distance learning? A study of student motives for taking internet -based courses at the high school and community college levels. Research on computing in Education, http://dx.doi.org/10.1080/08886504.1999.10782621

Saka, A. Y. O. (2006). A collection of essay in guidance and counselling for schools. Nigeria: Debis-co Printing and Press.

Sambo, S. (2008). Understanding guidance and counseling. Nigeria. Ahmadu Bello University.

Shertzer, B., \& Stone, S. C. (1976). Fundamentals of guidance. USA. Boston: Houghton Mifflin Company.

Tanglang, N., \& Aminu, K. I. (2014). Decision-making skills and academic performance of distance education learners: Implications for students counselors.

Tanglang, N., \& Aminu, K. I. (2015). Goal setting, decision-making skills and academic performance of undergraduate distance learners: Implications for retention and support services. Conference proceedings of the International Association for Development of the Information Society, ISBN: 978-989-8533-40-1. Secretariat@iadis.org

Zimmerman, B. J., \& Kitsantas, A. (1999). Acquiring writing revision skill: Shifting from process to outcome self-regulatory goals. Journal of Educational Psychology, 91, 241-250. http://dx.doi.org/10.1037/0022-0663.91.2.241 